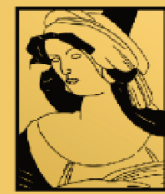

\title{
ALEXANDRIA
}

Revista de Educação em Ciência e Tecnologia

ALEXANDRIA

\section{Tudo São Fixações! Descrever o Mundo}

\section{Everything are Fixations! Describe the World}

\section{Rosilene Beatriz Machadoa ${ }^{\mathrm{a}}$ Cláudia Regina Flores ${ }^{\mathrm{a}}$}

a Departamento de Metodologia de Ensino, Universidade Federal de Santa Catarina, Florianópolis, Brasil rosilene.machado@ufsc.br, claudia.flores@ufsc.br

Palavras-chave:

Cartografia. História.

Imagem. Renascimento.

\section{Keywords:}

Cartography. History.

Image. Renaissance.
Resumo: Este artigo intenta problematizar, a partir da evidência da proliferação de mapas (visuais) no decorrer dos séculos XV a XVII, a entrada em cena de artefatos imagéticos (não apenas mapas, mas imagens em geral), até então descreditados em relação a fontes textuais, em uma cultura que historicamente vê-se fortemente dominada pela escrita. O questionamento é, afinal: o que tornou possível esse acontecimento (da proliferação de imagens)? O que se busca, portanto, é analisar que alterações são percebidas no estatuto epistemológico das imagens na produção do conhecimento a partir, especialmente, do período renascentista.

Abstract: This article tries to problematize, from the evidence of the proliferation of (visual) maps during the fifteenth to the seventeenth centuries, the entrance of imagery artifacts (not only maps, but images in general), hitherto unspecified in relation to textual sources, in a culture that historically finds itself strongly dominated by writing. The question is, after all, what made this event (of the proliferation of images) possible? What is sought, therefore, is to analyze what changes are perceived in the epistemological status of images in the production of knowledge from, especially, the Renaissance period. 


\section{Introdução}

Que é um geógrafo? perguntou o principezinho.

- É um sábio que sabe onde se encontram os mares, os rios, as cidades, as montanhas, os desertos.

É bem interessante, disse o principezinho. Eis, afinal, uma verdadeira profissão! E lançou um olhar, em torno de si, no planeta do geógrafo. Nunca havia visto planeta tão majestoso.

- O seu planeta é muito bonito. Haverá oceanos nele?

- Como hei de saber? disse o geógrafo.

- Ah! (O principezinho estava decepcionado.) e montanhas?

- Como hei de saber? disse o geógrafo.

- E cidades, e rios, e desertos?

- Como hei de saber? disse o geógrafo pela terceira vez.

- Mas o senhor é geógrafo.

- É claro, disse o geógrafo; mas não sou explorador (SAINT-EXUPÉRY, 2009, p. 28).

A produção de mapas aumentou exponencialmente ${ }^{1}$ - tanto em quantidade quanto em qualidade - entre os séculos XV e XVII, saltando de mil a milhões nesse interstício de tempo (WOODWARD, 2007, p. 11). Isso está, obviamente, relacionado à invenção da imprensa em meados do século XV, mas também, e principalmente, (se não como causa e efeito, certamente como um paralelo e mutuamente dependente fenômeno) à 'descoberta' de inumeráveis novas terras decorrente das chamadas grandes navegações. Isso porque, segundo Schulz (1987, p. 87), por um lado, os cartógrafos passavam a empenhar-se em corrigir rapidamente as imagens cartográficas herdadas de outros tempos e a transmitir as novas descobertas em suas publicações; por outro, patronos e exploradores estavam cada vez mais impulsionados a financiar e empreender novas viagens por conta das contradições implícitas e dos 'vazios' explícitos observados nos mapas.

Os mapas medievais (mappaemundi) ${ }^{2}$ tornavam-se inadequados às novas necessidades impostas, de forma que transformações passaram a ser requeridas. Em especial, novas soluções de modos de representação, tanto porque o mundo habitado encontrava-se consideravelmente expandido (em mais que o dobro do que era conhecido no período medieval), quanto, e sobretudo, porque à configuração sociocultural que se ia estabelecendo tornava-se fundamental estabelecer uma relação precisa entre as distintas localidades da terra. Assim, uma nova positividade foi sendo estabelecida; não uma 'revolução', mas a formulação de novas respostas a novos problemas, afinal, é evidente que os mapas medievais não poderiam corresponder às demandas que se impunham; eles constituíam-se em mapas históricos, em narrativas; sua função principal nunca foi de localização espacial, como agora se requeria, mas sim “instruir os fiéis sobre os eventos significativos na história cristã ao invés

\footnotetext{
${ }^{1}$ As análises aqui apresentadas são oriundas do trabalho de tese intitulado: Cartografia, Saber, Poder: Da emergência do desenho como disciplina escolar. Ver: Machado (2016).

${ }^{2}$ Mapas que representavam o mundo (conhecido) em sua totalidade.
} 
de registrar suas localizações precisas" (WOODWARD, 1987, p. 286, tradução nossa). É por isso que a emergência da cartografia moderna deve ser considerada como um 'acontecimento'. Acontecimento que tem na Renascença suas condições de possibilidade e que se dá em um jogo de transformações que se estabelecem e estabelecem novas relações. Que não se configura, portanto, em uma mudança brusca de mentalidade, ou uma lenta maturação rumo ao progresso. Que não é:

uma decisão, um tratado, um reino ou uma batalha, mas uma relação de forças que se inverte, um poder confiscado, um vocabulário retomado e voltado contra seus utilizadores, uma dominação que se enfraquece, se distende, se envenena e uma outra que faz sua entrada, mascarada (FOUCAULT, 1979, p. 28).

São três grandes categorias em que se pode enquadrar, segundo Woodward (2007, p. 12), as mudanças fundamentais que emergiram no campo cartográfico entre os séculos $\mathrm{XV}$ e XVI: mudanças internas quanto à estrutura dos mapas: sua lógica, linguagem e arranjo de seus elementos; mudanças na relação entre o mapa e o mundo observável, incluindo aí a quantificação e valorização da experiência, bem como um certo desapego à autoridade de textos geográficos clássicos, em função dos conflitos gerados pela observação direta do mundo; mudanças na relação entre mapas e sociedade por conta da disseminação de conhecimentos geográficos, provenientes, em grande parte, da invenção da imprensa e dos manuais produzidos por artesãos dedicados ao estudo de mapas.

Desse emaranhado de questões, talvez a principal seja o estabelecimento de uma nova concepção de espaço, colocada agora em termos abstratos. Ainda que no século XIII a obra de Roger Bacon, Opus Maius (1265), apresentasse indicativos de mapeamento por meio de um sistema de latitudes e longitudes, há uma escassez de mapas terrestres (sobreviventes) construídos sob tal premissa nos séculos XIII e XIV. Essa característica - a utilização do sistema de coordenadas descrito pelo geógrafo alexandrino Cláudio Ptolomeu em sua obra Geographia, e utilizado para o mapeamento celeste desde o período helenístico - é percebida com força somente a partir do século XV. Nele, assume-se uma superfície isotrópica e uniforme em que posições abstratas podem ser plotadas, tanto em mapas gerais do mundo ou em mapas de alguma região específica ${ }^{3}$.

Pois bem. Para além das alterações nas práticas cartográficas, operadas no decorrer dos séculos XV a XVII, gostaríamos de nos ater aqui, entrementes, sobre outro ponto: a proliferação de mapas (visuais) nesse período. Já indicamos a importância da invenção da imprensa na constituição desse fenômeno, bem como sua relação com as grandes navegações e 'novas descobertas'. Mas, ainda assim, o que se coloca em questão é a entrada em cena de artefatos imagéticos (e aí deve-se pensar não apenas em mapas, mas em imagens em geral), 
até então descreditados em relação a fontes textuais, em uma cultura que historicamente vê-se fortemente dominada pela escrita.

\title{
Do estatuto da imagem
}

Milhares de mapas foram produzidos entre os séculos XV e XVII e inúmeros atlas foram publicados. Em 1570, por exemplo, há a publicação do atlas de Abraham Ortelius, Theatrum orbis terrarum (Teatro do mundo), contendo 53 mapas, tendo sido reeditado em várias línguas e obtido diversas republicações. Em 1595 outro atlas, agora de Gerard Mercator, foi publicado, contendo 107 mapas, igualmente recebendo várias reedições e republicações. Pode-se citar ainda o atlas publicado por Braun e Hogenberg, Civitates orbis terrarum, entre 1572 e 1618, que pretendia ser um complemento ao atlas de Ortelius, apresentando 546 ilustrações de diversas cidades do mundo, sobretudo europeias. Tais como esses, tantos outros exemplos poderiam ser listados, mas não é esse o intuito aqui. Pensemos, isso sim, na problemática que se coloca: afinal, o que tornou possível esse acontecimento (da proliferação de mapas)?

Woodward (2007) aponta que é justamente a mudança na relação entre texto e imagem que é central para essa compreensão. "Não que o acelerado aumento de fontes gráficas tenha usurpado as funções da palavra escrita, mas que um novo idioma tenha sido adicionado ao antigo" (p. 12, tradução nossa). O que é alterado, portanto, é o estatuto epistemológico das imagens na produção de conhecimento, o que deu origem à ideia de que um mundo real e material poderia ser agora conhecido a partir da visão (SMITH, 2006).

Por um lado, é uma herança platônica a ideia mantida por séculos de que a imagem teria uma posição de inferioridade em relação ao texto escrito. Segundo Kern (2006), para o filósofo haveria duas formas de mimesis:

\begin{abstract}
a primeira, como essência, decorreria da criação demiúrgica, na qual o autor, a partir do modelo ideal, plasmava a ideia; a segunda, como imitação da aparência, seria originária da produção humana, vista como degradante, na medida em que se constituía apenas como um reflexo da realidade, e não como sua essência. A primeira permitiria o conhecimento da verdade e da realidade, constituindo-se como realidade inteligível, ao passo que a última criaria a ilusão do real e seria sua mera aparência sensível. Esta, ao simular o real, teria o poder de afetar a alma e de impedir o juízo racional (p. 17).
\end{abstract}

Por isso é que para Platão o poeta deveria ser considerado como um intérprete de Deus, como um ser superior em racionalidade, face ao pintor que só poderia reproduzir aparências. Já a imagem pictórica deveria ser considerada inferior, uma vez que era resultante de conhecimento sensível e não de conhecimento racional. Daí, enfim, a poesia deveria pertencer ao domínio do discurso e da razão (logos), "sendo inseparável da ordem inteligível 
e abstrata da linguagem, enquanto a pintura, ao ser construída por meio de linhas e cores, não atenderia as condições necessárias para ser considerada como tal" (KERN, 2006, p. 17).

Por outro lado, há que se considerar a predominância também da filosofia aristotélica no período renascentista, de forma que 'arte' era concebida tal qual Aristóteles a define em sua Ética a Nicômaco: "arte é disposição de produzir com reta razão" (Et. Nic., VI, 1040, apud KICKHOFEL, 2010, p. 167). Ainda, "toda arte é a respeito do vir a ser, isto é, de empregar arte e teorizar a respeito de como algo pode vir a ser ou não ser, cuja origem está naquele que faz, mas não na coisa feita" (Ibidem, p. 167). Isso implica que o termo estava ligado à ideia de "produzir a partir de princípios, mas não necessariamente os primeiros. (...) Em outras palavras, o termo arte significava manualidade ou a habilidade voltada a realizar algo material" (KICKHOFEL, 2004, p. 431).

Já o termo 'ciência' estava relacionado ao resultado abstrato da operação de separar o comum e o variável dentro de um determinado conjunto de experiências, "sendo o que era variável apenas um acidente em relação ao que era comum, sua essência” (Ibidem, p. 431). Assim sendo, ciência era tida como um corpo de conhecimentos que se organizava a partir de princípios definidos, cujo objetivo primeiro era o conhecimento das primeiras causas. Dizia Aristóteles que "um objeto de conhecimento científico existe por necessidade: é assim eterno, pois tudo o que existe por necessidade é eterno, e o que é eterno não vem a ser nem perece" (Et. Nic., VI, 1039, apud KICKHOFEL, 2010, p. 167).

Logo, em uma perspectiva aristotélica, ciência era uma 'disposição demonstrativa' enquanto arte era uma disposição da razão em relação a produções no mundo da geração e corrupção. "Essas definições estavam organizadas em uma hierarquia segundo a qual quanto mais afastado dos sentidos e das utilidades era um saber, mais elevado ele era" (KICKHOFEL, 2011, p. 322). Assim, defendia-se o afastamento das sensações comuns, priorizando-se as ciências não utilitárias, já que "o experiente é mais sábio do que aqueles que detêm uma sensação qualquer; o artífice, mais sábio do que os experientes; os mestres de obra, mais sábios do que os trabalhadores manuais, e as ciências teóricas, mais ciência do que as produtivas" (ARISTÓTELES, Metafísica, I, 981, apud KICKHOFEL, 2010, p. 169).

\footnotetext{
Nesses termos, a distinção entre os estudiosos da filosofia natural e os artistas do período em questão é simples e clara. Um artista utilizava seus conhecimentos empíricos - eventualmente formalizados sob a forma de desenhos, mas raramente sob a forma de um discurso sistemático - para realizar sua arte específica, como a pintura ou a escultura, entre diversas outras. Um filósofo natural formalizava sob a forma de discurso seus conhecimentos teóricos relacionados ao mundo físico. Entre ambos, existiram diferenças de objetivos, métodos e formas de realização de seus respectivos conhecimentos (KICKHOFEL, 2010, p. 432).
}

Se arte era entendida, portanto, como portadora de uma posição de inferioridade em relação à ciência, fica evidente que as imagens (fruto de uma operação artística) igualmente deveriam ser desqualificadas enquanto forma de conhecimento. Entretanto, conforme Kern 
(2006, p. 19), no período renascentista o conceito de criação artística, bem como as imagens, passaram a ser objeto de reflexão de artistas que reivindicavam a equiparação da pintura à poesia; ou até sua superioridade, como sustentava Da Vinci, argumentando que a pintura era uma forma própria de conhecimento, capaz de representar com muito mais intensidade do que as palavras figuras expressivas e em ação. Além do que, seus princípios de conhecimento eram superiores, exigindo do artista permanente investigação, tanto no campo da percepção, luzes, cores e pigmentos, quanto nos domínios da técnica e da natureza. "Foi a partir desse olhar que Leonardo afirmou a pintura como uma atividade mental que se situava como a mais elevada atividade do espírito e a reivindicou como ciência" (Ibidem, p. 20).

Mas não só artistas movimentaram reflexões em torno do estatuto das imagens nesse período; os naturalistas a partir de fins do século XVI também logo começaram a reivindicar o elevado poder de comunicação de fontes imagéticas e gradativamente passaram a incorporálas nos manuais ilustrados que surgiam pela Europa. Leonhard Fuchs, no prefácio de seu $D e$ historia stirpium (Comentários notáveis sobre a história das plantas), em 1542, é enfático nesse ponto:

\begin{abstract}
Ainda que as figuras tenham sido preparadas com grande esforço e suor, nós não sabemos se no futuro elas estarão condenadas como inúteis e sem importância e se alguém citará a mais insípida autoridade de Galeno para defender que ninguém que quiser descrever plantas tentará fazer figura delas. Mas por que tomar mais tempo? Quem em sua sã consciência condenaria figuras que podem transmitir informação muito mais claramente do que a palavra do homem mais eloquente? (FUCHS, 1542, apud SMITH, 2006, p. 86, tradução nossa).
\end{abstract}

Pouco mais de uma década depois da publicação de Fuchs, Georgio Agricola (considerado o 'pai' da geologia como ciência) também afirmava em seu De re metallica, de 1556, uma superioridade das imagens frente aos textos antigos:

Eu não somente os descrevi (os objetos, ferramentas e processos da mineração), como também contratei ilustradores para delinear suas formas, para que as descrições que são transmitidas por palavras fossem compreendidas por homens do nosso tempo, ou para não causar dificuldades à posteridade, da mesma forma como para nós frequentemente causam dificuldade os muitos nomes que os Antigos nos transmitiram sem qualquer explicação (AGRICOLA, 1556, apud SMITH, 2006, p. 87 , tradução nossa).

Andréas Vesalius, em seu tratado de anatomia intitulado De humanis corpori fabrica, publicado em 1543, igualmente já teria dito que "as ilustrações ajudam muito a compreensão, uma vez que elas colocam mais claramente diante dos olhos o que o texto descreve" (VESALIUS, 1543, apud SMITH, 2006, p. 87, tradução nossa). Importante ressaltar que essa ênfase na precisão visual e no potencial comunicativo das imagens era frequentemente acompanhada por uma espécie de ênfase na observação em primeira pessoa e na prova a partir da testemunha ocular. "As imagens tornaram-se uma importante forma de gravar, coletar, 
catalogar e testemunhar o curioso, o maravilhoso e o particular" (SMITH, 2006, p. 89, tradução nossa).

As figuras a seguir dão a ver e pensar potentes elementos para um melhor entendimento desse panorama que se vê esboçado no período:

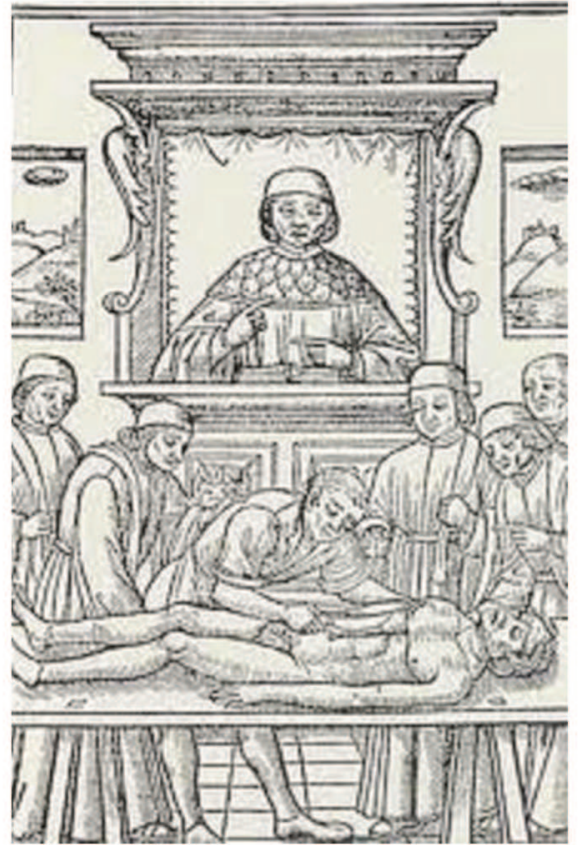

Figura 1- Frontispício da Anatomia, de Mondino. Imagem estampada na edição genebriana de 1519.

Fonte: Chiarello (2011, p. 292).
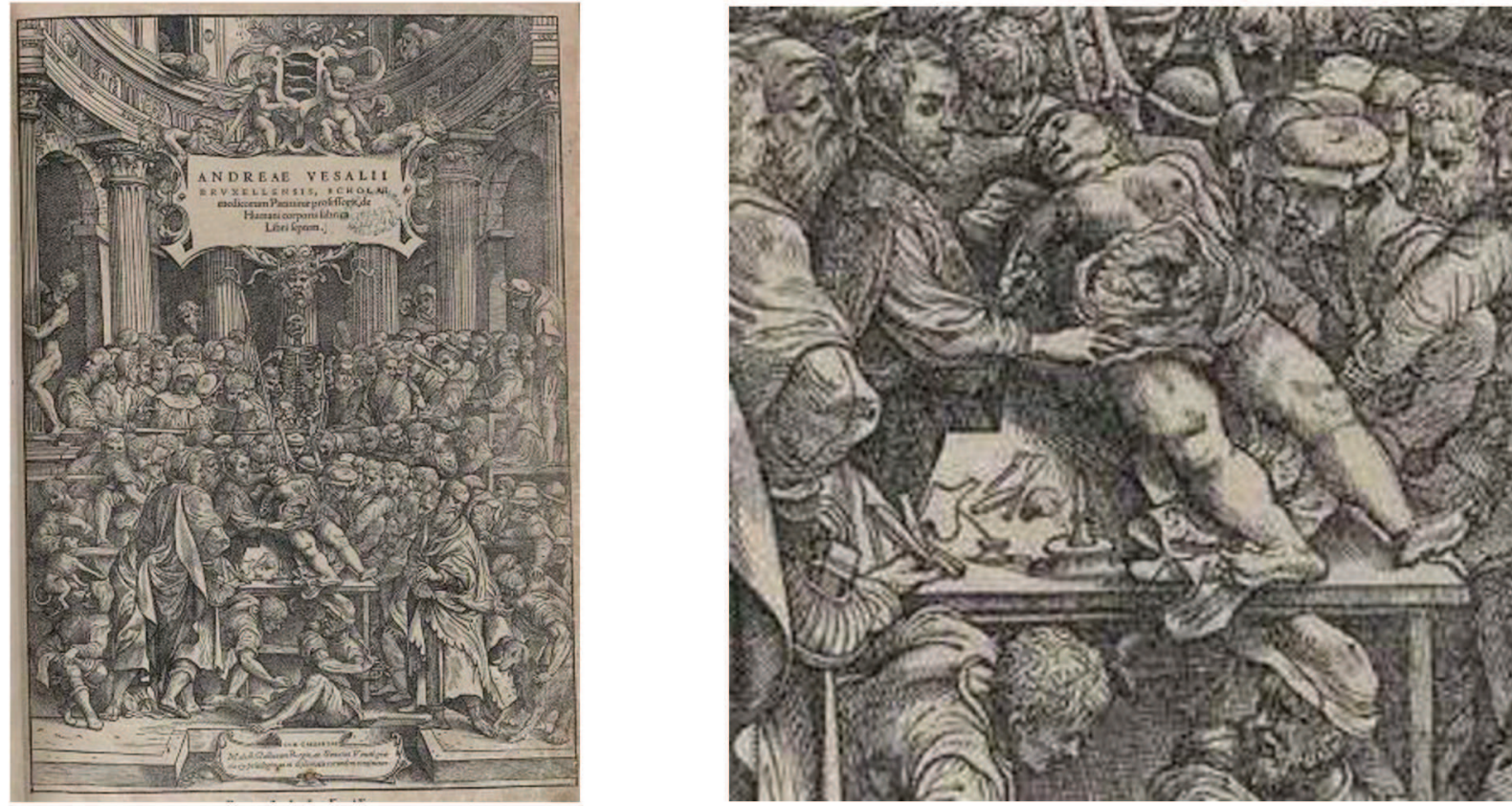

Figura 2 - Frontispício do De humani corporis fabrica de Vesalius. Imagem estampada na edição de Basiléia de 1543. Ao lado, detalhe do mesmo frontispício.

Fonte: Chiarello (2011, p. 295-296). 
A Figura 1 representa a condução de uma sessão de dissecação do corpo humano ${ }^{4}$. Essa imagem está estampada no manual conhecido como De Anatome, publicado em 1315 por Mondino de Liuzzi (1270-1326), utilizado como referência para estudos anatômicos por quase três séculos. A Figura 2, estampada no manual de anatomia De humani corporis fabrica, publicado em 1543, também representa uma sessão de anatomia, mas dessa vez conduzida pelo médico Andreas Vesalius (1514-1564).

$\mathrm{Na}$ primeira imagem a palavra é soberana. Pode-se até mesmo inferir que esse frontispício lá está mais para ser lido do que visto. Os traços que o compõe não delineiam mais que os contornos vazios de uma figura sem volume em uma cena quase sem profundidade. No alto e no centro da cena está a autoridade suprema de cuja palavra emana a verdade e cujo discurso principia e finaliza o que acontece no plano inferior da gravura.

Mas o lector não a vê. Seu domínio é o da elocução, e não o da visão, e aqui é a elocução que determina a visão. Suas palavras conferem à dissecção sua razão de ser, orientam todo o procedimento de incisão, tornam inteligível o corpo humano em suas formas e estruturas, mas seu olhar paira imperturbável sobre o plano da ação (CHIARELLO, 2011, p. 291).

Durante o período medieval e início da Renascença a atividade do professor de anatomia era tão somente expor a tradição textual. Tal era o poder das palavras que aquele que as proferia não era o mesmo que realizava o procedimento da dissecação. Cabia a um cirurgião iletrado ir abrindo o cadáver, ao passo que um professor assistente deveria ir apontando as estruturas guiadas pelos textos escolásticos, em geral, os escritos de Galeno, Avicena e Mondino. O saber emanava dos livros clássicos, fonte máxima de autoridade, que guiava a dissecação: "nada se executa sobre o corpo humano que a palavra antes não ordene, nada se descobre no corpo humano que a palavra antes não exponha, nada se percebe sobre o corpo humano que o livro, autoridade suprema, antes não revele" (Ibidem, p. 293).

Na segunda imagem a situação é diametralmente oposta:

\begin{abstract}
Um amplo espaço sustentado por colunas monumentais em semicírculo encontra-se superlotado, e todos nele se concentram como se assistissem a um espetáculo há muito aguardado. Há volume nas figuras sombreadas e profundidade na cena. A perspectiva da gravura é primorosa. Não obstante as inúmeras e diferentes personagens que poderiam extraviar nossa atenção, nosso olhar é irresistivelmente arrastado para o ponto de fuga da cena, ponto para o qual também convergem os olhares de tantos quantos ali se aglomeram. Neste ponto vemos um cadáver já aberto cujas entranhas, a saltar da cavidade abdominal, oferecem-se abertamente. Os olhares de todos nelas se fixam, e nelas também mergulha nosso olhar (CHIARELLO, 2011, p. 295).
\end{abstract}

Para além do uso da técnica da perspectiva presente nessa gravura, outros detalhes são bastante instigantes. Note-se, inicialmente, que é o próprio Vesalius quem conduz a dissecação; além disso, o cadáver dissecado é de uma mulher e os livros existentes na imagem

\footnotetext{
${ }^{4}$ As análises que seguem, quanto às práticas anatômicas, são provenientes dos estudos realizados em trabalho prévio. Ver Machado e Flores (2013).
} 
estão fechados, sendo até difícil observá-los entre tantos elementos representados. Há ainda no detalhe da Figura 19, para onde especialmente quero chamar atenção, uma folha de papel, uma pena, um tinteiro e a mão de um desenhista, próximos ao cadáver.

Desenho dentro do desenho, e espaço em branco em meio ao espaço repleto da cena, a folha de papel ali está posta como um convite para ser preenchida. Mesmo o olhar que Vesalius nos endereça, a nós que admiramos o frontispício, reconduz nosso olhar para o papel do desenhista logo abaixo (CHIARELLO, 2011, p. 296).

Desenho dentro do desenho. De fato, pela primeira vez teve-se publicado um livro de anatomia em que texto e imagem aparecem conjugados. No De humani corpori fabrica existem mais de duzentas ilustrações, divididas em três categorias: o esqueleto, os músculos, e as partes individuais do corpo. Nesse livro, a imagem não assume posição inferior a do texto escrito, ambos complementam-se, não sendo o desenho concebido apenas como ilustração, mas como consolidação dos conhecimentos obtidos na mesa de dissecação. "Cada imagem era acompanhada de um texto escrito por Vesalius, de forma que um não poderia ser entendido sem o outro, formando um todo inseparável” (ZANIRATO, 2011, p. 42).

Isso posto, perceba-se, por um lado, que com Vesalius não mais é o texto que orienta a observação e a experiência realizadas sobre o corpo humano; inversamente, são a observação e a experiência que se reproduzem no texto de anatomia. Há um deslocamento, então, do reino da oratio para o domínio da perceptio (CHIARELLO, 2011, p. 295). O lugar da evidência deixa de ser o que revelam os livros consagrados, que dão lugar à observação direta sobre o corpo humano.

Tal deslocamento significa, no limite, o descrédito das antigas fontes de autoridade prescritas pela escolástica: salta aos olhos o quanto é falho e imperfeito o saber por elas enunciado. Mas não significa a exclusão do livro enquanto lugar de elaboração teórica. O livro não mais aparece, é certo, como repositório do saber consagrado, mas continua presente enquanto espaço destinado não só ao registro e à documentação, como à formulação de novos conhecimentos a respeito da anatomia humana (CHIARELLO, 2011, p. 299).

Por outro lado, é a imagem, e não somente o texto escrito, que viabiliza o registro da observação e experiência, tornando-se indispensável nos tratados de anatomia: “o grande mérito de Vesalius reside, destarte, nas descrições detalhadas e nas ilustrações anatômicas primorosas, ambas resultantes de uma observação prática acurada realizada fervorosamente" (Ibidem, p. 301, grifos nossos). 


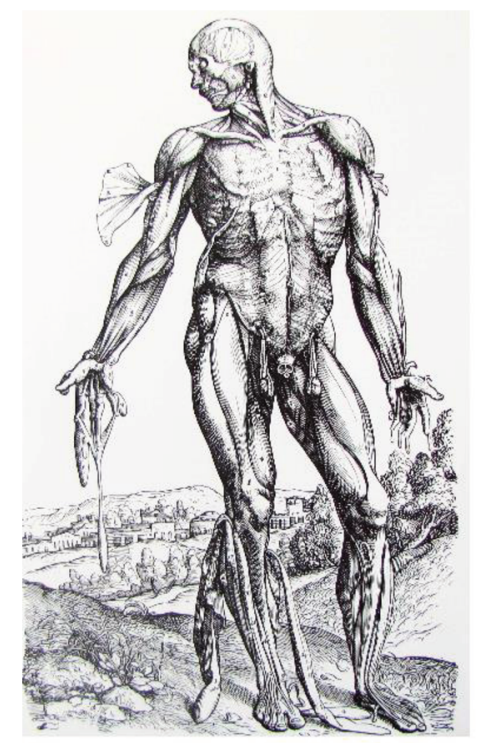

Figura 3 - Andreas Vesalius. De humani corporis fabrica, 1543.

Fonte: Zanirato (2011, p. 56).

No período anterior a Vesalius a rudeza das ilustrações "mostra o pouco interesse pelas artes dos artífices por parte dos professores de anatomia". A partir daí, "a inclusão de gravuras nos tratados de anatomia ocorreu aos poucos, e inclusive Vesalius teve de enfrentar resistências por utilizá-las em seu grande livro de 1543" (KICKHOFEL, 2011, p. 331). O que interessa, com efeito, é que uma cultura visual lentamente iniciava-se em função do "descobrimento de técnicas de ilustração desenvolvidas nos ateliês dos artistas renascentistas e à intensa atividade editorial da época, que lentamente descobria o "poder da ilustração'" (Idem, 2003, p. 397).

É assim que a imagem, a partir do Renascimento, começou a experimentar novos papéis, na transição de uma cultura de memória e instrução para uma cultura de descoberta e invenção. Se, antes, uma de suas funções era servir como recurso facilitador na compreensão de determinado assunto por parte dos não letrados, daqueles incapazes de apreender o discurso escrito, agora, aos poucos, passava a adquirir poder explicativo equiparável ao das palavras ao possibilitar descrever com maior exatidão as observações advindas da experiência.

\section{Da Descriptio}

Multiplicaram-se, portanto, as imagens e mudou-se seu estatuto epistemológico na produção do conhecimento. Mas o tipo de conhecimento que se vê florescer nesses 'novos tempos' é também outro. Um conhecimento, como se percebe, que se quer agora descritivo.

A habilidade artesanal na representação naturalista deu origem a uma nova estética e engendrou uma viva demanda pela representação semelhante à vida, que, quando combinada com a exploração de novas terras e a exploração comercial de recursos naturais, produziu uma cultura de descrição de testemunha ocular e representação 
que ajudou as pessoas a olhar com novos olhos o seu próprio mundo (SMITH, 2006, p. 90).

Descrever o mundo - eis, então, o novo ideário que se estabelece. Ideário que tem na imagem seu efeito e suporte. É essa a configuração emergente no período renascentista e que se concretiza no século XVII. Robert Hooke, em seu Micrographia ${ }^{5}$, publicado em 1664, não poderia dar melhor veredito a esse respeito. Dizia ele que seus estudos tinham por objetivo:

mostrar que para isso [ver em um microscópio ou telescópio] não se requer muita coisa, nenhuma força da Imaginação, ou exatidão do Método, ou profundidade da Contemplação (embora a adição destas, ali onde se deve possuí-las, deva produzir uma serenidade mais perfeita), mas sim uma Mão sincera e um Olho fiel, para examinar, e para registrar, as coisas tais quais elas aparecem (HOOKE, 1664, apud ALPERS, 1999, p. 161, grifos da autora).

De acordo com Alpers (1999), com o Micrographia, Hooke pensava estar contribuindo com uma 'reforma na filosofia'. Era o olho, auxiliado pela lente, que permitia passar do mundo ilusório do cérebro e da fantasia para o mundo concreto das coisas. "E o registro dessas observações visuais, que eram o assunto do seu livro, devia ser a base para um novo e verdadeiro conhecimento" (p. 161).

Olhos que veem e mãos que registram. A partir dessa premissa é que descrições botânicas, anatômicas, médicas, topográficas, cartográficas, dentre tantas outras, foram se constituindo e ganhando espaço e primazia na ordem do saber instituída dentre os séculos XVI e XVII, especialmente. Se vivesse nesses tempos, então, o geógrafo de Saint-Exupéry teria deixado o principezinho menos decepcionado. Saberia dos oceanos, das montanhas, das cidades, rios e desertos porque os teria testemunhado, observado. Porque teria deixado sua escrivaninha e olhado o mundo mais de perto...

Do que foi dito até aqui, pensamos que fica claro, pois, que o fenômeno da exorbitante produção de mapas está intrinsecamente colado à função que esse artefato passou a assumir nesse período, não mais, como outrora, de narrativa de eventos históricos, mas sim, de descrição. Se, como argumentamos, a imagem é efeito e suporte de um novo ideário descritivo do mundo, obviamente também o deve ser o mapa, já que se presta a descrever os territórios desse mundo que agora se abre à observação e ao inquérito.

De fato, conforme Alpers (1999, p. 247), "os autores ou editores de mapas eram referidos como 'descritores do mundo', e seus mapas ou atlas como o mundo descrito." A A arte de pintar, de Vermeer, figura como uma espécie de afirmação paradigmática nesse sentido:

\footnotetext{
${ }^{5}$ Obra que apresenta descrições detalhadas de cinquenta e sete observações microscópicas e três observações telescópicas.
} 


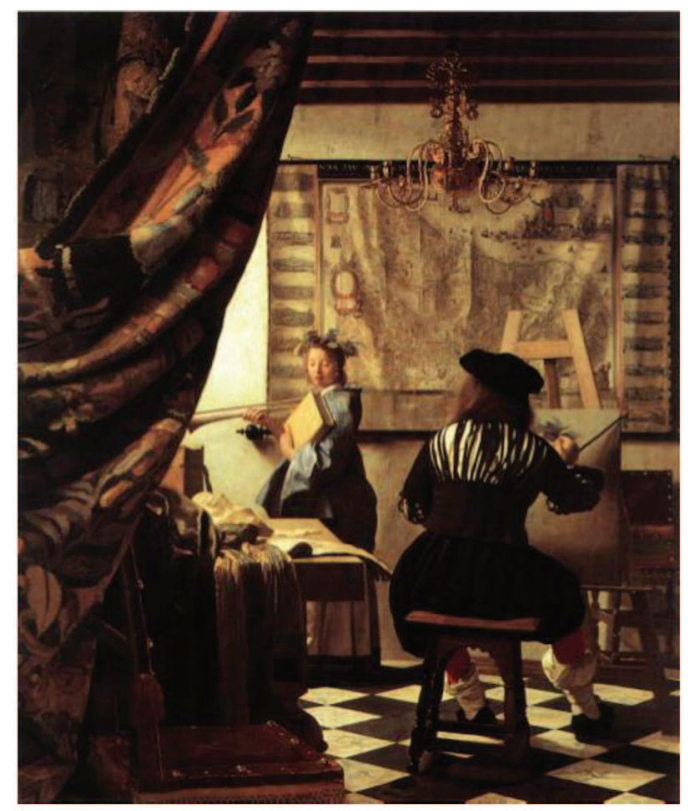

Figura 4 - Johannes Vermeer. A arte de pintar. 1666.

Fonte: Web Gallery of Art. Disponível em: https://www.wga.hu/support/viewer/z.html

Uma análise mais pontual do imenso e belíssimo mapa que literalmente 'rouba' a cena revela a função a que ele corresponde:
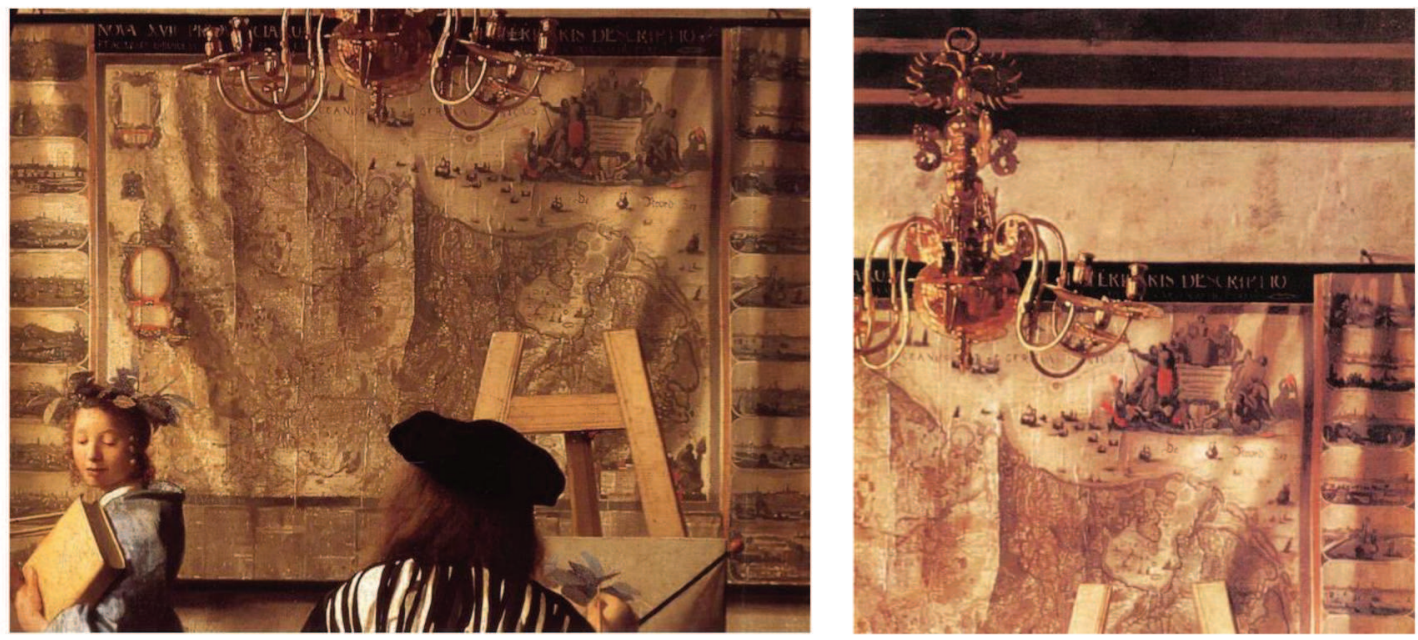

Figura 5 - Detalhes da obra A arte de pintar, Johannes Vermeer, 1666.

Fonte: Web Gallery of Art. Disponível em:

https://www.wga.hu/support/viewer/z.html e https://www.wga.hu/support/viewer/z.html

Descriptio. Esse é o termo que intitula o mapa e aparece com toda clareza em sua borda superior direita. Se Vermeer o deixa evidente é porque, provavelmente, era já uma prática comum que a palavra descriptio compusesse os títulos dos mapas que se produziam em seu tempo. E aí, a questão que se coloca é: quais foram as condições de possibilidade para a emergência desse novo tipo de conhecimento, então descritivo?

Pode-se ficar tentado a responder que foram as novas descobertas responsáveis por essa emergência. Entretanto, tal argumentação não se sustenta se levada a um exame mais 
acurado. Ora, é perfeitamente possível que novas terras tivessem sido descobertas sem que o impulso descritivo (e cartográfico) que percebemos florescer tivesse despontado (o período em que aconteceram as cruzadas é um bom exemplo disso). O que acontece, efetivamente, é que "o modo de ser das coisas e da ordem que, distribuindo-as, oferece-as ao saber, é que foi profundamente alterado" (FOUCAULT, 2007, p. XIX).

O saber da cultura ocidental, que perdurou até o fim do período renascentista, foi construído sob o pilar da semelhança: pela interpretação das marcas que Deus havia depositado sobre o mundo. Foi ela que guiou a exegese e a interpretação dos textos, que permitiu o conhecimento das coisas visíveis e invisíveis. É dessa maneira que:

no tesouro que nos transmitiu a Antiguidade, a linguagem vale como o signo das coisas. Não há diferença entre essas marcas visíveis que Deus depositou sobre a superfície da Terra, para nos fazer conhecer seus segredos interiores, e as palavras legíveis que a Escritura ou os sábios da Antiguidade, esclarecidos por uma luz divina, depositaram nesses livros que a tradição salvou (FOUCAULT, 2007, p. 46).

Assim é que a relação que se dava com os textos era da mesma natureza que a relação com as coisas: em ambas eram signos que se buscava apontar e fazer falar. Mas, enquanto na natureza havia figuras semeadas por Deus a serem decifradas, os textos já eram interpretações dadas pelos antigos que não tinham senão que serem recolhidos e interpretados. "Uma vai da marca muda à própria coisa (e faz falar a natureza); a outra vai do grafismo imóvel à clara palavra (restitui vida às linguagens adormecidas)" (Ibidem, p. 46).

Logo, tal como os sinais da natureza estavam ligados pela relação de semelhança ao que indicavam, também o discurso produzido na Antiguidade estava ajustado às próprias coisas, era feito à imagem do que ele anunciava. Por isso é que portavam intrinsecamente seu título de autoridade, já que eram um tesouro de signos que por similitude ${ }^{6}$ se ligavam ao que podiam designar. "A verdade de todas essas marcas - quer atravessem a natureza, quer se alinhem nos pergaminhos e nas bibliotecas - é em toda a parte a mesma: tão arcaica quanto a instituição de Deus" (Ibidem, p. 46).

Dessa forma,

\footnotetext{
${ }^{6}$ Foucault (2007) indica quatro principais figuras que prescreveram suas articulações ao saber da semelhança. Primeiro a convenientia: "são 'convenientes' as coisas que, aproximando-se umas das outras, vêm a se emparelhar; tocam-se nas bordas, suas franjas se misturam, a extremidade de uma designa o começo da outra" (p. 24). O mundo é a conveniência universal das coisas: há tantos peixes na água quanto animais sobre a terra; na água e sobre a superfície tantos seres quanto os há no céu e aos quais correspondem, etc.. Segundo, a aemulatio: uma espécie de conveniência, mas atuando à distância, sem contato. "Há na emulação algo do reflexo e do espelho: por ela, as coisas dispersas através do mundo se correspondem. De longe, o rosto é o êmulo do céu e, assim como o intelecto do homem reflete, imperfeitamente, a sabedoria de Deus, assim os dois olhos, com sua claridade limitada, refletem a grande iluminação que, no céu, expande o sol e a lua" (p. 26). Terceiro, a analogia: nela superpõe-se convenientia e aemulatio. "Como esta, assegura o maravilhoso afrontamento das semelhanças através do espaço; mas fala, como aquela, de ajustamentos, de liames, e de juntura. (...) A relação, por exemplo, dos astros com o céu onde cintilam, reencontra-se igualmente: na da erva com a terra, dos seres vivos com o globo onde habitam, dos minerais e dos diamantes com as rochas onde se enterram, dos órgãos dos sentidos com o rosto que anima, das manchas da pele com o corpo que elas marcam secretamente." (p. 29). Por fim, a quarta forma de semelhança dá-se pela simpatia: "ela é princípio de mobilidade: atrai o que é pesado para o peso do solo e o que é leve para o éter sem peso; impele as raízes para a água e faz girar com a curva do sol a grande flor amarela do girassol" (p. 32).
} 
entre as marcas e as palavras, não difere a observação da autoridade aceita ou o verificável da tradição. Por toda a parte há somente um mesmo jogo, o do signo e do similar, e é por isso que a natureza e o verbo podem se entrecruzar ao infinito, formando, para quem sabe ler, como que um grande texto único (FOUCAULT, 2007, p. 47).

A linguagem, portanto, não era concebida como um conjunto de signos independentes em que as coisas refletir-se-iam tal qual em um espelho, mas antes, misturava-se com as figuras do mundo e se imbricava com elas, formando uma rede de marcas. Assim sendo, da mesma forma que as coisas escondiam e manifestavam seus segredos como uma linguagem, ao mesmo tempo as palavras se colocavam aos homens como coisas a serem decifradas. "Um tal entrelaçamento da linguagem com as coisas, num espaço que lhes seria comum, supõe um privilégio absoluto da escrita" (Ibidem, p. 52). É essa primazia da escrita que explica a não distinção entre o que se via e o que se lia, entre o observado e o relatado, "da constituição, pois, de uma superfície única e lisa, onde o olhar e a linguagem se entrecruzam ao infinito" (Ibidem, p. 54) - tal como se pôde perceber na análise das práticas anatômicas no período anterior ao século XVI. É próprio desse saber nem ver nem demonstrar, mas tão somente interpretar.

Segundo Foucault (2007), em fins do Renascimento consolidou-se a suspensão do primado da escrita. A profunda interdependência da linguagem e do mundo se achava finalmente desfeita, assim como a camada uniforme em que se entrecruzavam indefinidamente o visto e o lido, o visível e o enunciável. "As coisas e as palavras vão separar-se. O olho será destinado a ver e somente a ver; o ouvido somente a ouvir. O discurso terá por tarefa dizer o que é, mas não será nada mais que o que ele diz" (p. 59). Abriu-se, doravante, o espaço de um saber em que a questão não seria mais a das similitudes, mas a da identidade e das diferenças. Um saber em que a comparação não teria mais a função de revelar a ordem intrínseca ao mundo; mas de seguir a ordem do pensamento, indo naturalmente do simples ao complexo.

Desde então, o texto cessa de fazer parte dos signos e das formas da verdade; a linguagem não é mais uma das figuras do mundo nem a assinalação imposta às coisas desde o fundo dos tempos. A verdade encontra sua manifestação e seu signo na percepção evidente e distinta. Compete às palavras traduzi-la, se o podem; não terão mais direito a ser sua marca. A linguagem se retira do meio dos seres para entrar na sua era de transparência e neutralidade (FOUCAULT, 2007, p. 77, grifos nossos).

Compete às palavras traduzi-la [a percepção evidente e distinta], se o podem. Entretanto, se não o podem, o que seria capaz de assumir essa função de representação transparente, livre de resíduos e opacidade? Claro parece estar que foi a representação gráfica - a imagem, o desenho - que passou a cumprir esse papel. Todo o regime de signos foi alterado a partir da primeira metade do século XVII. Se antes estava imerso no 'jogo da semelhança', depositando sua visibilidade na ordem da própria 'coisa', agora a teoria dos 
signos, nesse projeto de uma ciência geral da ordem, passa a ser analisada não mais em termos de repetição, mas de representação (FOUCAULT, 2007). É uma teoria dual que se coloca em contraposição à teoria ternária que a antecede:

\begin{abstract}
a teoria do signo implicava três elementos perfeitamente distintos: o que era marcado, o que era marcante e o que permitia ver nisto a marca daquilo; ora, este último elemento era a semelhança - o signo marcava na medida em que era 'quase a mesma coisa' que o que ele designava. É esse sistema unitário e triplo que desaparece ao mesmo tempo que o 'pensamento por semelhança', e que é substituído por uma organização estritamente binária (Ibidem, p. 88).
\end{abstract}

Logo, “a partir da idade clássica, o signo é a representatividade da representação enquanto ela é representável", ou seja, se antes os signos eram apenas "meios de conhecer e chaves para um saber; são agora co-extensivos à representação, isto é, ao pensamento inteiro" (FOUCAULT, 2007, p. 80, grifos do autor). O signo assume, dessa forma, uma relação binária entre significado e significante, em um "espaço onde nenhuma figura intermediária assegura mais seu encontro: ela é, no interior do conhecimento, o liame estabelecido entre a ideia de uma coisa e a ideia de uma outra" (Ibidem, p.79).

Na relação significante-significado, o conteúdo, função e determinação do significante contém somente aquilo que ele representa: "ele lhe é inteiramente ordenado e transparente; mas esse conteúdo só é indicado numa representação que se dá como tal, e o significado se aloja sem resíduo e sem opacidade no interior da representação do signo" (FOUCAULT, 2007 , p. 89). É por isso que, de fato, um exemplo primeiro de signo é "a representação espacial e gráfica - o desenho: mapa ou quadro" (Ibidem, p. 89):

\begin{abstract}
a pintura e o mapa são considerados como exemplos primeiros de um signo. Um signo que passa a estabelecer uma relação binária, pois ele dá a ver aquilo que não está presente aos olhos. Portanto, signo é um objeto que representa um outro objeto. Assim, da mesma forma que acontece com a pintura de uma cena, de um retrato, o mapa manifesta uma verdadeira relação entre a coisa e sua representação, a tal ponto que nos leva a pensar que um mapa é a cidade, o país ou o globo (FLORES, 2003, p. 84).
\end{abstract}

Tudo isso levou a uma nova ordem do saber que tinha, sempre manifestada, a necessidade de interrogar a origem dos conhecimentos. Não à toa, é nesse período que se percebe a emergência das chamadas ciências empíricas; essa transformação na ordem do saber é que foi, afinal, sua condição de possibilidade. As imagens, então, "informações de um novo tipo, transmitem o que não se pode dizer: as observações sem conclusões e o seu cortejo de questões, as intuições explicativas, as certezas dos resultados obtidos (SICARD, 2006, p. 23-24).

Mas, ressalte-se, essa nova ordem do saber que se vê esboçada, ancorada na necessidade de interrogar a origem dos conhecimentos, só é possível porque está colada à instituição de uma nova forma de verdade, a que Foucault (2013) chama de inquérito (enquête): “inquérito tal como é e como foi praticado pelos filósofos do século XV ao século 
XVIII, e também por cientistas, fossem eles geógrafos, botânicos, zoólogos, economistas - é uma forma bem característica da verdade em nossas sociedades" (p. 21). Com ela:

\begin{abstract}
Os desenhos e as gravuras, resultantes de uma observação direta e rigorosa, substituem a pouco e pouco as criaturas nascidas das paixões dos discursos. As imagens guiam a observação, tornam-se instrumentos de determinação. Abandonam o caráter de vinhetas decorativas suscetíveis de dar apoio a variados textos. Nas obras de zoologia, passam a ocupar o lugar mais importante.

(...)

A imagem gravada passa a ter uma função de difusão dos saberes. Deve expor na perfeição as características de reconhecimento: a forma das escamas, a posição das barbatanas ou das bárbulas junto à boca. Como corolário, as diferenças entre as espécies tornam-se mais rigorosas. O rodovalho, o linguado e a dourada distinguemse claramente. A imagem abre a via do diálogo, da crítica: as formas da natureza tornam-se objeto de discussão (SICARD, 2006, p. 62).
\end{abstract}

A origem do inquérito apareceu como uma forma de pesquisa da verdade no interior da ordem jurídica e, procurando descobrir quem fez o quê, em que condições e momento específicos, é "que o Ocidente elaborou as complexas técnicas do inquérito que puderam, em seguida, ser utilizadas na ordem científica e na ordem da reflexão filosófica" (Ibidem, p. 21). A transformação na ordem do saber, dada efetivamente em fins do século XVI é, na verdade, a transformação das formas de verdade que se deslocam do domínio da prova para o domínio do inquérito.

Sob o regime da prova, em caso de contestação ou litígio, o estabelecimento da verdade nunca se dá por testemunho ou constatação. São outros mecanismos que se colocam em ação. No direito feudal, por exemplo, quando um indivíduo apresentava alguma reivindicação ou contestação, acusando outra pessoa de ter matado ou roubado, a questão era resolvida por uma série de provas aceitas por ambos e a que eram submetidos. "Esse sistema era uma maneira de provar não a verdade; mas a força, o peso, a importância de quem dizia" (Ibidem, p. 62).

Um tipo de prova corrente eram as provas sociais. Nesse caso, o acusado poderia tranquilamente atestar sua inocência através da reunião de doze testemunhas que jurassem que ele não havia cometido aquilo pelo que era acusado. Note-se que a prova de inocência, alicerçada no juramento das testemunhas, não estava de forma alguma fundada no testemunho; mas relacionada, tão somente, ao peso e à influência social do indivíduo.

Outro tipo de prova eram as provas verbais. Nestas, o acusado deveria responder à acusação com um certo número de fórmulas, sendo que, ao pronunciá-las, poderia ter fracasso ou sucesso. "Em alguns casos pronunciava-se a fórmula e perdia-se. Não por haver dito uma inverdade ou por se provar que havia mentido, mas por não ter pronunciado a fórmula como devia" (Ibidem, p. 63). Havia também as chamadas provas mágico-religiosas. O acusado deveria prestar juramento e, caso não ousasse ou hesitasse, dava-se o processo como perdido. Por fim, existiam ainda as provas corporais. Eram chamadas ordálios e aqui o acusado era 
submetido a uma espécie de luta consigo mesmo, com seu próprio corpo, para constatar sua vitória ou fracasso.

Disso, o que é importante observar é que:

No sistema da prova judiciária feudal trata-se não da pesquisa da verdade, mas de uma espécie de jogo de estrutura binária. O indivíduo aceita a prova ou renuncia a ela. Se renuncia, se não quer tentar a prova, perde o processo de antemão. Havendo a prova, vence ou fracassa. Não há outra possibilidade (FOUCAULT, 2013, p. 64).

A prova comporta, pois, quatro características básicas: exige sempre dois adversários; termina por uma vitória ou um fracasso; não é necessário haver a presença de um terceiro personagem para distinguir os dois envolvidos; e não serve para localizar quem disse a verdade, mas para estabelecer quem é mais forte no jogo estabelecido; quem, portanto, tem razão. Foi esse sistema de práticas judiciárias que desapareceu e se viu transformado em fins da Idade Média em novas formas de justiça:

\footnotetext{
Formas que são absolutamente capitais para a história da Europa e para a história do mundo inteiro, na medida em que a Europa impôs violentamente o seu jugo a toda superfície da terra. O que foi inventado nessa reelaboração do Direito é algo que, no fundo, concerne não tanto aos conteúdos, mas às formas e condições de possibilidade do saber. $O$ que se inventou no Direito dessa época foi uma determinada maneira de saber, uma condição de possibilidade de saber, cujo destino vai ser capital no mundo ocidental. Esta modalidade de saber é o inquérito (Ibidem, p. 65).
}

Esse inquérito judiciário acabou difundindo-se em muitos outros domínios de práticas e em muitos domínios do saber. Conforme Foucault (2013), a partir dos séculos XIV e XV apareceram tipos de inquérito que tinham por objetivo estabelecer a verdade a partir de um certo número de testemunhos minuciosamente levantados em campos como o da geografia, astronomia, conhecimento dos climas, etc. "Aparece, em particular, uma técnica de viagem, empreendimento político de exercício de poder e empreendimento de curiosidade e de aquisição de saber, que conduziu finalmente ao descobrimento da América” (Ibidem, p. 76)

Sendo assim, todo o grande movimento cultural que começou a preparar o Renascimento "pode ser definido em grande parte como o desenvolvimento, o florescimento do inquérito como forma geral de saber" (Ibidem, p. 77). Forma que buscará saber e ver o que efetivamente foi dito, o que foi lido nos textos; que visará conhecer tão bem o que foi dito quanto à natureza a respeito da qual algo foi dito; que verificará o que os autores disseram pela constatação da natureza; que utilizará, enfim, os autores não mais como autoridade mas como testemunho.

\section{Das fixações}

De tudo isso, pensamos que a análise sobre o que tornou possível a emergência e proliferação de mapas (de imagens em geral) no período renascentista está bem delineada. Se esse acontecimento se deu é porque toda uma transformação na ordem do saber foi operada, 
de maneira que a função desempenhada pelos mapas passou a corresponder às novas necessidades que tal ordem impunha. Na Inglaterra de inícios do século XVI, por exemplo,

\begin{abstract}
a delimitação das propriedades se realizava de uma maneira tradicional. Existem poucos mapas de campos medievais, mas em geral o conceito de 'denominação e marcação das fronteiras' para definir a propriedade implicava a definição prática de 'medidas e fronteiras', e deram origem a esses passeios paroquiais em que, diz-se, os jovens mais notáveis do coro juvenil davam golpes com uma vara no chão para designar assim pontos importantes: daí a expressão 'bater as fronteiras'. Em caso de disputa, devia-se recorrer a doze homens 'bons e justos' para declarar sob juramento a verdade das declarações verbais sobre os limites, e seu testemunho deveria ser recolhido textualmente. (...) Isto começou a mudar na década de 1570 , quando apareceu uma forma cartográfica inteiramente nova (BUISSERET, 2004, p. 174, tradução nossa).
\end{abstract}

Essa forma cartográfica inteiramente nova a que se refere Buisseret (2004) são os chamados mapas de propriedade que 'invadiram' a Inglaterra (e posteriormente outros países da Europa) em fins do século XVI. Em havendo disputa, seriam eles, a partir daí, que teriam o poder de atestar sobre a regularidade ou não das fronteiras e limites das propriedades. Cumprindo essa mesma função descritiva, impulsionado por um conjunto diverso de elementos, os mapas do mundo, mapas corográficos, mapas topográficos, despontaram e multiplicaram-se a partir do Renascimento.

Tudo são fixações? Sim... "Meus caros, a verdade é esta: tudo são fixações. Hoje vocês se fixam de um modo e amanhã, de outro" (PIRANDELLO, 2004, p. 59).

\title{
Referências
}

AGRICOLA, G. De re metallica. Trans. Herbert Clark Hoover and Lou Henry Hoover. New York: Dover, 1950.

ALPERS, S. A arte de Descrever: A Arte Holandesa no Século XVII. Tradução Antonio de Pádua Danesi - São Paulo: Ed. da Universidade de São Paulo, 1999.

ARISTÓTELES. Ética a Nicômaco. Tradução de Leonel Vallandro e Gerd Bornheim da versão inglesa de W. D. Ross In: Os Pensadores. São Paulo: Nova Cultural, 1973, v.4.

ARISTÓTELES. Metafísica. Ensaio introdutório, texto grego com tradução e comentário de Giovanni Reale. São Paulo: Loyola, 2001.

BUISSERET, D. La revolución cartográfica en Europa, 1400-1800. La representación de los nuevos mundos en la Europa del Renacimiento, Barcelona: Paidós Orígenes, 2004,

CHIARELLO, M. Sobre o nascimento da ciência moderna: estudo iconográfico das lições de anatomia de Mondino a Vesalius. Scientia \& Studia, v. 9, n. 2, p. 291-317, 2011.

FOUCAULT, M. As palavras e as coisas. 9ª ed., São Paulo: Martins Fontes, 2007.

FOUCAULT, M. A verdade e as formas jurídicas. Rio de Janeiro: Nau, 2013.

FUCHS, L. De historia stirpium. Basel, 1542. 
KERN, M. L. B. Imagem Manual: Pintura e Conhecimento. In: FABRIS, A.; KERN, M. L. B. (org.). Imagem e Conhecimento, São Paulo: Ed. da Universidade de São Paulo, 2006. p. 1530.

KICKHOFEL, E. H. P. Uma falsa lição de anatomia ou de um simples caso de impregnação teórica dos fatos. Scientia \& Studia, v. 2, n. 3, p. 427-443, 2004.

KICKHOFEL, E. H. P. Aristóteles, Alberti e a ciência do pintor. O Que nos Faz Pensar, Rio de Janeiro, n. 27, mai., p. 165-183, 2010.

KICKHOFEL, E. H. P. A ciência visual de Leonardo da Vinci: notas para uma interpretação de seus estudos anatômicos. Scientia \& Studia, v. 9, n. 2, p. 319-355, 2011.

HOOKE, R. Micrographia. Londres, 1665.

MACHADO, R. B.; FLORES, C. R. O Corpo Despido pelas Práticas de Desenhar: Dos Usos à Disciplinarização do Desenho. Bolema, v. 27, n. 45, p. 255-279, 2013.

MACHADO, R. B. 2016. Cartografia, Saber, Poder: Da emergência do desenho como disciplina escolar. Tese (Doutorado em Educação Científica e Tecnológica), Universidade Federal de Santa Catarina, Florianópolis, SC, Brasil, 2016.

PIRANDELLO, L. Um, nenhum e cem mil. São Paulo: CosacNaify, 2004.

SAINT-EXUPÉRY, A. O pequeno príncipe. Rio de Janeiro: Ed., 2009. Aquarelas do autor. $48^{a}$ edição / 49 reimpressão. Tradução por Dom Marcos Barbosa.

SICARD, M. A fábrica do olhar: imagens de ciência e aparelhos de visão (século XV-XX). Lisboa: Edições 70, 2006.

SMITH, P. H. Art, Science, and Visual Culture in Early Modern Europe. Isis, Chicago, 2006.

VESALIUS, A. De Humani Corporis Fabrica. Epitome. Tabulae sex. Trad. Pedro Carlos Piantino e Maria Cristina. Coedição: Imprensa Oficial-SP/Ateliê Editorial/Editora Unicamp, 2002.

WOODWARD, D. Medieval Mappaemundi. In: HARLEY, J.; WOODWARD, D. (org.). The History of Cartography, vol. I, Chicago, The Chicago University Press, 1987, p. 286-370.

WOODWARD, D. Cartography and the Renaissance: Continuity and Change. In: HARLEY, J.; WOODWARD, D. (org.). The History of Cartography, vol. III, Chicago, The Chicago University Press, 2007, p. 3-24.

ZANIRATO, B. S. L. Em busca da realidade: A representação do corpo na anatomia e na pintura do Renascimento. 2011. 97f. Monografia (Graduação em História) - Universidade Federal do Paraná, Curitiba, 2011.

\section{SOBRE AS AUTORAS}

ROSILENE BEATRIZ MACHADO. É docente do Departamento de Metodologia de Ensino do Centro de Ciências da Educação da UFSC. É licenciada em Matemática, mestre e doutora em Educação Científica e Tecnológica pela UFSC. 
CLÁUdiA REGINA FLORES. É docente do Departamento de Metodologia de Ensino do Centro de Ciências da Educação da UFSC e professora credenciada no Programa de PósGraduação em Educação Científica e Tecnológica (UFSC). É licenciada em Matemática, mestre e doutora em Educação, linha Ensino de Ciências e Matemática, pela UFSC. Tem orientado projetos de Iniciação Científica, Mestrado e Doutorado em temas ligados à História, à Arte e à Visualização em interação com a Educação Matemática. É bolsista Produtividade em Pesquisa - CNPQ desde o ano de 2011 e coordena o Grupo de Estudos Contemporâneos e Educação Matemática (GECEM), criado em 2009.

Recebido: 01 de agosto de 2017.

Revisado: 22 de fevereiro de 2018.

Aceito: 10 de maio de 2018. 